\title{
Conformity Assessment as a Tool for Organizational Learning in Large Engineering and Construction Projects
}

\author{
Luciano Assalim', Maria Fatima Ludovico de Almeida²
}

\begin{abstract}
For the successful realization of large engineering and construction projects (LECPs), a systemic organizational learning framework for institutional cooperation is critical. Due to the long project life-cycle of LECPs, this is particularly important for this kind of project. The objective of this paper is to analyze to what extent the conformity assessment of LECPs, carried out under Engineering, Procurement and Construction management (EPCm) services, can be used as a tool for organizational learning and cooperation between typical stakeholders (project owners, engineering contractors, EPC contractors; subcontractors and certification bodies). The research, from which this paper emanates, was based on a case study concerning LECPs in an oil and gas company in Brazil. Based on its results, we suggest that the proposed organizational learning framework, supported by the conformity assessment rationale, constitutes an important management tool that can be disseminated in other organizational contexts where conformity assessments of LECPs take place.
\end{abstract}

Keywords: conformity assessment; project management; organizational learning; engineering projects; epc contracts.

'Bureau Veritas Brasil; Praça Pio X, 17, 9th floor, Rio de Janeiro, Brazil, 20040-020; Phone: 055212206 9200. E-mail: assalim@gmail.com ${ }^{2}$ Master Program on Metrology, Quality and Innovation; Pontifical Catholic University of Rio de Janeiro; Rua Marquês de São Vicente, 225, Rio de Janeiro, Brazil, 2247I-I50; Phone: 0552I 3527I542. E-mail: fatima.ludovico@puc-rio.br 


\section{Introduction}

By 2030 non-OECD energy consumption will be $69 \%$ above the 2010 level, with growth averaging $2.7 \%$ p.a. (or I.6\% p.a. per capita), and it accounts for $65 \%$ of world consumption (BP, 2012). In absolute terms, this means that in these countries the processing capacity that has to be implemented during the next 15 years is more than twice in relation to the last decades. From this perspective, owners in the oil and gas industry in non-OECD countries are facing an overheated contracting market for engineering and construction projects. This situation is expected to continue for a considerable number of years, which will significantly affect the way projects for new processing facilities are developed and implemented.

Large engineering and construction projects (LECPs) for new processing facilities in the oil and gas industry are technically complex, encompassing the integration of many different technical disciplines on the basis of a large codified body of knowledge. The technical complexity can be better illustrated by the high level of technical availability (typically over $95 \%$ ) during the lifetime of the facility (typically 20-25 years). This places high demands on the quality of the technical development and implementation process to achieve the required functionality.

Their lifecycle from beginning to the end of execution is typically longer than six years and large sum is spending on a single megaproject. The industry statistics report that more than $65 \%$ of these LECPs are failing to meet their contract goals which can bring all sorts of problems to an organization. This low performance can be highly attributed to the level of definition and planning achieved during the Front End Engineering Design (FEED) phase of large engineering and construction projects (LECPs). The risks on LECPs are high mainly due to: (i) the large investment yields no revenue until after implementation; (ii) the facility is indivisible with limited possibilities to reduce exposure through breaking up the scope of work; (iii) transferring the facility to another location is generally not feasible with limited options for redeployment of equipment; and (iv) development and implementation times are long, typically $2-3$ years and $3-5$ years, respectively (Berends, 2007).

Faced with this scenario, the development and implementation of LECPs in oil and gas industry constitute a continuous organizational change process, involving a large number of institutions or stakeholders, as showed in Figure I: (i) the owner of the facility (and its shareholders), lenders, export credit agencies, insurers, etc.; (ii) contractors (licensors, engineering contractors, EPC contractors, suppliers of equipment and materials, etc.); (iii) governmental authorities, local communities, non-governmental organizations, etc.; (iv) customers and feedstock suppliers; and ( $\mathrm{v}$ ) certification bodies.

Mapping out the requirements of key stakeholders prior to LECPs execution offers the opportunity to identify issues involved with the project and also strategies to deliver the respective level of expectations according to each party involved. The project teams as key stakeholders must be capable of and committed to delivering the proposed execution strategy as well as engage and inform other stakeholders throughout the whole project's life cycle (Senger, 2012).

For the successful realization of LECPs, a systemic organizational learning framework for institutional cooperation is required (rather than traditional project control procedures). Due to the long project life-cycle of LECPs, this is particularly important for this kind of project. In this paper,

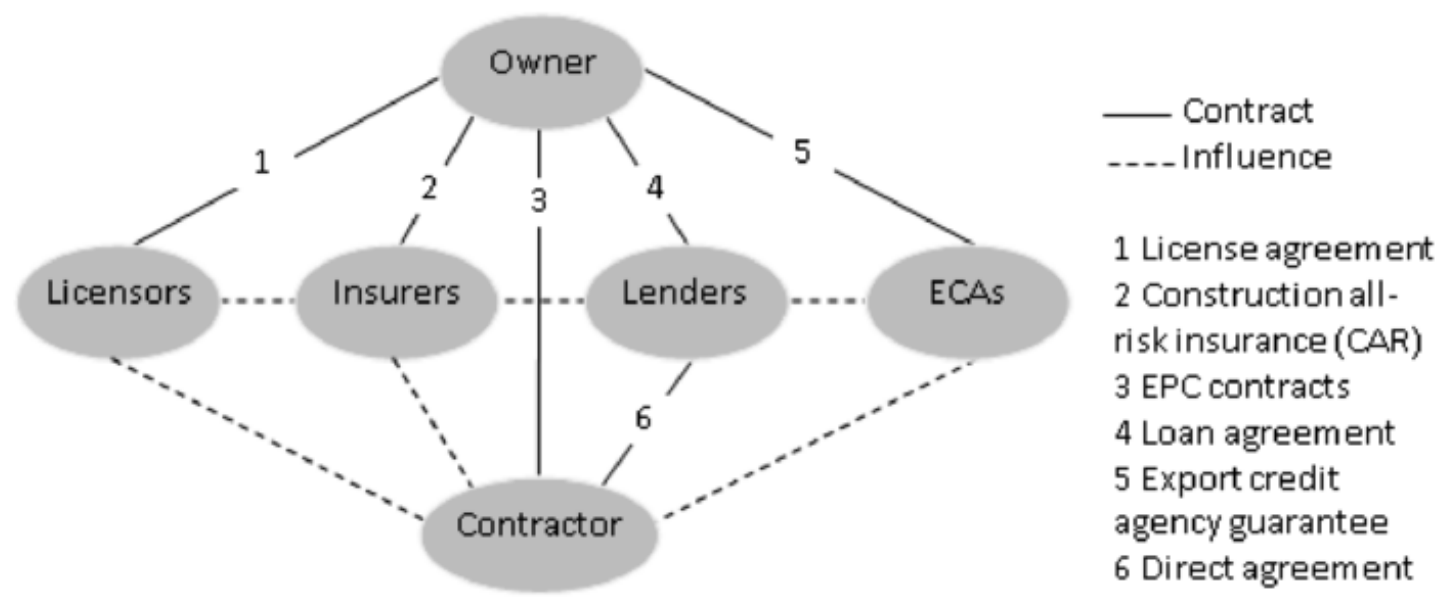

Figure I.Typical stakeholder agreement schema in LECPs context. Source: Berends, 2009.

ISSN: 07I 8-2724. (http://www.jotmi.org)

Journal of Technology Management \& Innovation (c) Universidad Alberto Hurtado, Facultad de Economía y Negocios. 
the emphasis will be on the engineering, procurement and construction (EPC) contracts, formalizing the relationship between owner and contractor(s). Within this context, it is appropriate to consider the practice of conformity assessment by a third party (certification body), focusing on the early stages of LECPs - Front End Loading (FEL) and executive phases.

The conformity assessment by a third party aims to ensure that contractors achieve or surpass the performance levels required by the market (cost, timing, quality of services) and also regulatory compliance. From this perspective, the role of certification bodies is quite significant because they strongly contribute to the consolidation of a systemic organizational learning framework during the early stages of a given LECP.

This paper aims at analyzing to what extent the conformity assessment of LECPs, carried out under EPC management (EPCm) services, can be used as a tool for organizational learning and cooperation between typical stakeholders. The research, from which this paper emanates, was based on a case study concerning LECPs in an oil and gas company in Brazil. The objects of analysis are three LECPs in Brazil carried out by the Petrobras' Engineering Services. These projects were related to marine terminals to be operated in this country by Transpetro, a subsidiary of Petrobras. The projects are: (i) Pecém - Tecém Marine Terminal (Ceará State); (ii) Barra do Riacho Marine Terminal (Espírito Santo State); and (iii) Ilha Comprida Marine Terminal (Rio de Janeiro State).All three projects were developed under engineering, procurement and construction (EPC) contracts.

For Petrobras, the company focused in the case study presented in this paper, the EPC approach relies on assigning the responsibility for investigations, design and construction to the contractor for a lump sum price determined through competitive bidding. The objective is to ensure implementation of its LECPs to specified standards with a fair degree of certainty relating to costs and time.

Due to problems that Petrobras began to face in relation to the quality of EPC services, by 2000 the company reviewed its strategy of outsourcing with an emphasis on monitoring services from the early phases of its LECPs. Since then, Petrobras has been adopting a new strategy that consists of an ongoing monitoring by the Executive Management of Engineering Services, from the early stages of its large projects. Supporting this strategy, the conformity assessment by a third party emerged as an effective mechanism to check the compliance (by EPC contractors) with specified standards and contractual specifications, as well as compliance with regulatory requirements. The evaluation mechanism by a third party has been used by Petrobras for providing ad- ditional confidence in the whole project, based on assumptions such as independence, recognized technical competence, confidentiality and impartiality of certification bodies, i.e. neutrality in relation to possible conflicts of interests between the project owner and contractors.

For the conformity assessment concerning FEED phase of the three marine terminals projects, Petrobras hired the Bureau Veritas Brazilian branch. This certification body offers an extensive range of technical services and solutions in the fields of certification, conformity assessment, consulting and training in most of its eight business lines which are: marine, industry, in service verification, system certification services, health \& safety, construction, government services \& international trade, and consumer products.

Finally, the motivation of this research originated from the previous job analysis during the process of conformity assessment process carried out by Bureau Veritas focusing on the three mentioned LECPs in Petrobras. This preliminary analysis indicated that early detected inconsistencies could significantly contribute to identify critical engineering documents in FEED phase and to map recurrent errors and their causes, in the light of the conceptual approach of organizational learning outlined by Argyris and Schön (1996).

\section{Theoretical background}

The theoretical background encompasses the following themes: (i) large engineering and construction projects in the oil and gas industry; (ii) conformity assessment; (iv) organizational learning (OL), emphasizing the conceptual approach outlined by Argyris and Schön (1996).

\section{Large Engineering and Construction Projects in the Oil and Gas Industry}

The 1970s saw the international oil companies executed most of the Engineering, Procurement and Construction management $(E P C m)$ of projects themselves. Small and medium size projects were executed by local organisations and LECPs by central engineering and project organisations. During the 1970s, these EPCm capabilities, once considered to be the exclusive domain of the international oil companies, started to shift to international engineering and construction contractors (ECs). Initially, EC involvement was limited to occasional drafting services for detailed engineering. During the 1980s, however, the profits of the oil companies plummeted, leading to a focus on cost reduction and core competencies (Berends, 2007). This included outsourcing of most of the functions during the development and implantation of their LECPs. Over time, the ECs expanded their services to procurement and eventually companies emerged capable of tackling all EPCm activities (Rooij van and Homburg, 2002). 
EPC management is a prominent form of contracting agreement in the global oil and gas industry. The engineering and construction contractors carry out the detailed engineering design of the LECP, procure all the required equipment and materials, and then construct to deliver a functioning facility or asset to their clients. Companies that deliver EPC projects are commonly referred to as EPC contractors. The EPC phase of the project is also known as the execution phase which normally follows what is known as a Front-End Loading (FEL) phases. FEL refers to as pre-project planning (PPP), front-end engineering design (FEED), feasibility analysis, conceptual planning, programming/schematic design and early project planning.

The FEED is a basic engineering design used as the basis for the EPC phase. The FEED can be divided into separate packages covering different portions of the project. The FEED packages are used as the basis for bidding on when the client offers the EPC work to the market. In general, the EPC contractor has to execute and deliver the project within an agreed time and budget, commonly known as a Lump Sum Turn Key (LSTK) contract. An EPC LSTK contract places the risk for schedule and budget on the EPC contractors (Merrow, 20I I).

The project owner or client to the EPC contractors will normally have a presence in the EPC contractor's offices during the execution of the EPC contract. The Client places a project management team or PMT to overlook the EPC contractor. The PMT will ensure that the EPC contractor is carrying out the works in accordance with the agreed scope of works and in accordance with the contract. An agreed LSTK scope of works and price will be negotiated and agreed between EPC contractor and the project owner during the execution of EPC activities (Merrow, 20I I).
As mentioned before, LECPs are fragile as they are more sensitive to the quality of services, and are more difficult to manage, because of their complexity. According to Merrow (20II), 65\% of major LECPs fail around the world and a key factor for this poor performance is the level of definition achieved at the Front End Engineering Design (FEED) phase. Poor definitions make projects prone to changes during construction when project costs are at highest (Senger, 20I2). LECPs in the oil and gas industry encompass the outsourcing of engineering, procurement, construction, and management services at a value anywhere greater than $80 \%$ of the total installed costs (Senger, 20I2).

Figure 2 shows how significant value can be created by the project owner during early stages of the project management process. On the other hand, too many definitions can destroy value, once the project can be no longer synchronized with other critical objectives and elements of the organizational environment.

As LECPs become larger and more complex there has been an increasing tendency of compression schedule in order to put the end product into the market earlier and hence generate revenues earlier.This movement is clearly compromising the planning/definition phase of LECPs and leading to poor results. As the owner fast-track their projects, the execution phase is mostly overlapping the definition phase. Nevertheless, changes become more complex and more costly as they occur later in the project life-cycle (Harris et al, 2004; Senger, 2012).

Table I shows values for error correction in each phase of a given LECP. It is observed that potential errors are properly anticipated and avoided in definition phase of the project and impacts on costs will be significantly lower than when errors detection takes place only in the execution phase

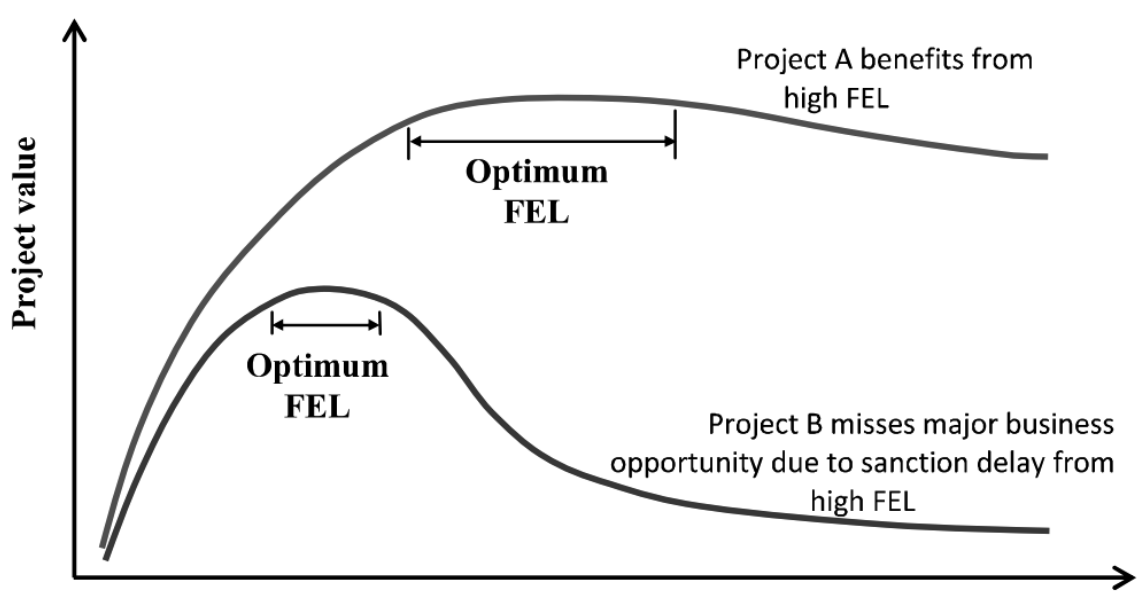

Time spent in FEL/amount of FEL

Figure 2. The net value of definition in LECPs. Source: Lowes and Van Driel, 2004.

ISSN: 07I 8-2724. (http://www.jotmi.org)

Journal of Technology Management \& Innovation (c) Universidad Alberto Hurtado, Facultad de Economía y Negocios. 
and final delivery of the project. In this sense, in definition phase of LECPs should receive greater attention from project owners and EPC contractors.

\section{Conformity assessment}

For the purposes of this research, we define conformity assessment according to ISO IEC I7000:2005 (ISO / IEC, 2005), as follows: " demonstration that specified requirements relating to a product, process, system, person or body are fulfilled". The scope of activities of conformity assessment includes testing, inspection and certification, and accreditation of conformity assessment bodies.

Showing that a product, service or system meets certain requirements by conformity assessment has a number of benefits: (i) it provides consumers with added confidence; (ii) it gives the company a competitive edge; and (iii) it helps regulators ensure that health, safety or environmental conditions are met. The main forms of conformity assessment are certification, inspection and testing. Although testing is the most widely used, certification is the best known. Certification is the provision by an independent body of written assurance (a certificate) that the product, service or system in question meets specific requirements. Certification is also known as third-party conformity assessment.

\section{Organizational learning}

According to Argyris and Schön (1996), learning involves the detection and correction of error. Where something goes wrong, it is suggested, to look for another strategy that will address and work within the governing variables. Given or chosen goals and values (governing variables), plans and rules are operationalized rather than questioned. The authors called it as single-loop learning. An alternative is to question to governing variables themselves, to subject them to critical scrutiny. This phenomena is a doubleloop learning that may lead to change governing variables and, thus, a shift in the way in which strategies, actions and consequences are framed.

When the error detected and corrected permits the organization to carry on its present guidelines and policies or achieve its presents objectives, then that error-and-correction process is single-loop learning. Single-loop learning seems to be present when goals, values, frameworks and, to a significant extent, strategies are taken for granted. The emphasis is on techniques and making techniques more efficient.Any reflection is directed toward making the strategy more effective.

\begin{tabular}{|l|l|}
\hline Relative costs & LECP life-cycle phases \\
\hline $1 \times$ costs & Definition \\
\hline $10 \times$ costs & FEED phase \\
\hline $100 \times$ costs & Execution \\
\hline $1000 \times$ costs & Final delivery of the project \\
\hline
\end{tabular}

Table I. Costs related to each life-cycle project phase. Source: Rufino (20II)

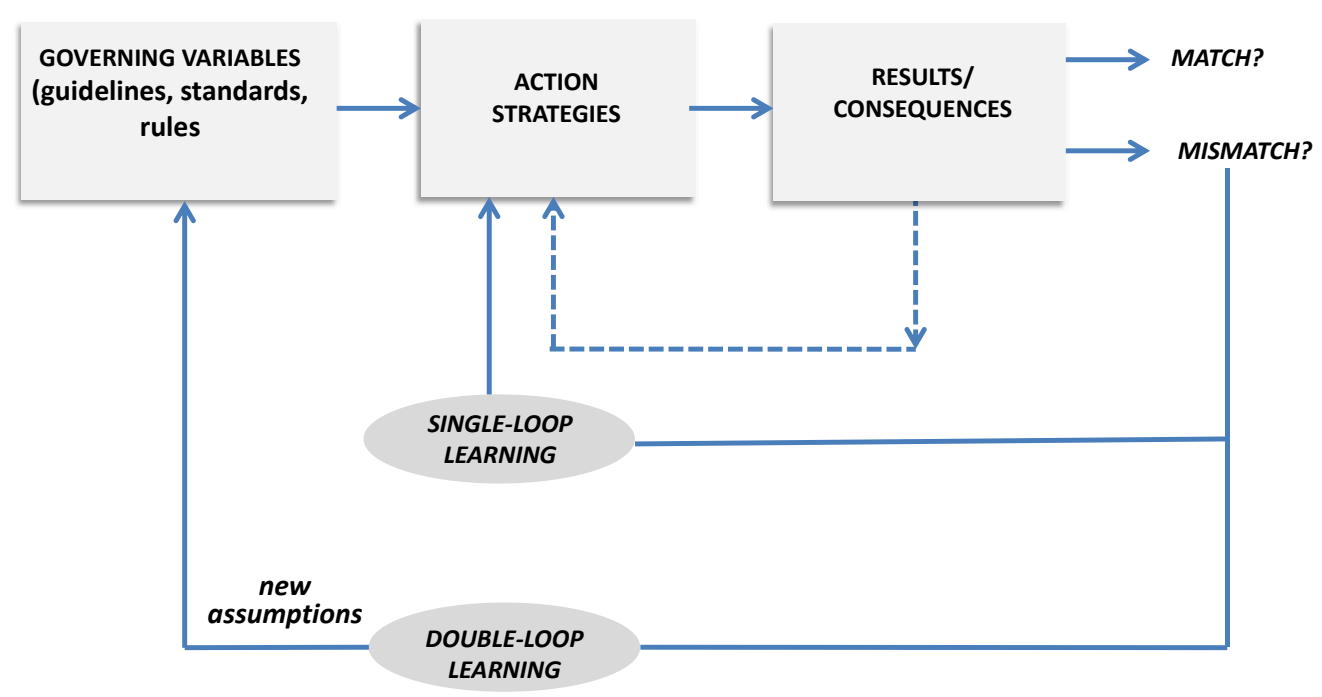

Figure 3. Organizational learning according to Argyris and Schön (1996)

ISSN: 07 I8-2724. (http://www.jotmi.org)

Journal of Technology Management \& Innovation (c) Universidad Alberto Hurtado, Facultad de Economía y Negocios. 
Double-loop learning, in contrast, occurs when error is detected and corrected in ways that involve the modification of an organization's underlying norms, policies and objectives. Reflection here is more fundamental: "the basic assumptions behind ideas or policies are confronted... hypotheses are publicly tested... processes are disconfirmable not self-seeking" (Argyris and Schön, 1996, p.32).

Figure 3 shows schematically how single-loop and doubleloop learning according to the theoretical approach outlined by Argyris and Schön (1996).

The evolutionary view of learning implies that there can be no learning without a reflexive action. From ideas of single and double-loop learning (Argyris and Schön, 1996), debate emerged about distinctions between incremental and transformational change and boundaries between the two. From cognition-behavior debate on organizational learning, it is important to mention the analysis presented by Fiol and Lyles (1985). They state that "it is essential to note the difference between cognition and behavior, for not only do they represent two different phenomena, but also one is not necessarily an accurate reflection of the other" (1985, p. 804). They also suggest that learning involves changes in cognition, while adaptation involves changes in behavior.

From the transition management perspective, Kerkhof and Wieczorek (2005, p.736) reconceptualise organizational learning as "a collective process in which stakeholders generate new insights into, and a better understanding of, the different perceptions, ideas, interests, and (normative) considerations that exist with regard to the nature of the transition themes, as well as with regard to the appropriate strategies to induce the transition (i.e., the objects of learning). These new insights may lead to a change in actors' way of thinking and to joint actions that aim to contribute to inducing the specific transition (i.e., the results of learning)".

\section{Methodology}

The research encompassed three phases: (i) exploratory research, (ii) applied research, and (iii) conclusive phase. In the exploratory phase, a bibliographical review focusing on the research central themes was carried out. As presented in the previous section, these themes are: (i) large engineering and construction projects in the oil and gas industry; (ii) conformity assessment; (iv) organizational learning (OL), emphasizing the conceptual approach outlined by Argyris and Schön (1996). The review of the literature assisted in identifying the patterns of different contractual mechanisms commonly adopted by the oil and gas industry and in revealing how FEED can affect project performance.
At the applied research phase, we adopted a case study strategy, following the method proposed by Yin (2005). It included a documentary research about the organizational context and the external environment of Petrobras Engineering Services and compilation of information on the three marine terminals projects, particularly engineering documents. A job analysis with direct observation during the conformity assessment process and organization of data collection assisted in: (i) identifying critical documents generated in Front End Engineering Design (FEED) phase of each selected project; and (ii) detecting and mapping the major errors and lessons learned in this phase (FEED). Based on the typology presented by Yin (2005), we selected the type of case study that best suited the research question: embedded single case study, considering a single general context, a major unit of analysis and three units incorporated, as mentioned in the introduction. In this embedded single case study, attention was paid to the three sub-units and this helped to focus the inquiry and increased the sensitivity of data collection.

The development of the case study comprised four stages: (i) design the case study protocol; (ii) proposal of an integrated conformity assessment (CA)/organizational learning (OL) framework; (iii) conduct the case study, preparing for data collection and organizing data collected; (iv) analyze case study evidence, by identification of critical documents, major mistakes and lessons learned from the three projects selected marine terminals, (v) develop conclusions, recommendations, and implications based on the evidence and validation of the integrated CA/OL framework.

Finally, the conclusive phase sought to make recommendations to the stakeholders involved (project owner, engineering contractors, EPC contractors, sub-contractors and certification body). At that phase, prospects for future studies were identified, particularly for empirical studies associated with the implementation of the integrated $\mathrm{CA} / \mathrm{OL}$ framework developed during the research and described in this paper.

\section{Analytical model of conformity assessment as a tool for organizational learning}

Large engineering and construction projects (LECPs) for new processing facilities in the oil and gas industry - as discussed in this paper - comprise a definition phase; FEED phase; execution; and final delivery of the project. The FEED phase are performed by engineering contractors, being execution and final delivery performed by contractors (EPCs) and their subcontractors. The certification of the project by a third party - in this case the Bureau Veritas Brazil - aims to ensure that the project, once executed, showing that its object is safe to operate within the operating conditions and assumptions previously established. 
An analytical model of conformity assessment as a tool for organizational learning was proposed and empirically validated by both project teams (Petrobras and Bureau Veritas) in the context of Bureau Veritas Brazil certification of the three Petrobras' marine terminals projects: (i) Pecém - Tecém Marine Terminal (Ceará State); (ii) Barra do Riacho Marine Terminal (Espírito Santo State); and (iii) llha Comprida Marine Terminal (Rio de Janeiro State).

The modeling phase was based on the theoretical branch of organizational learning developed by Argyris and Schön (1996) and also on the program evaluation model proposed by Forss, Cracknell and Samset (1994). The model design relied on the most updated stream of the program evaluation field. This stream explores the evaluation as a continuous process of learning within the organization (Preskill and Torres, 200I, Russ-Eft and Preskill, 200I). The learning approach has gained increased visibility in academia and government areas, and has opened important spaces for future applications in business context, as in the Petrobras case study here described.

The model is schematically represented in Figure 4 . It seeks to emphasize the existence of a connection between the organizational knowledge structure and the conformity assessment as a mechanism for organizational learning.

In order to check the results from its projects and actions, the organization needs appropriate feedback mechanisms. The conformity assessment emerges as one of the most important feedback mechanisms available nowadays for organizations searching excellence. It is able to detect errors in the way the organization acts, indicating how to correct them, and helping to improve organizational efficiency and effectiveness.
Conformity assessment can generate organizational learning, from the moment in which the organization seeks to use systematically this feedback mechanism, either instrumental or in a conceptual way, in order to improve or change the way it acts. As mentioned before, two types of learning can be generated depending on the use of conformity assessment by the organization: (i) single-loop learning that promotes changes in the way it acts, keeping the structure of dominant knowledge structure or governing variables, and (ii) double-loop learning, which requires fundamental changes in the structure of the dominant knowledge organization. When the organization uses the information generated by the process of conformity assessment (compliances and non-compliances) to improve its performance, but basically remains the same existing knowledge structures, it is said that it will be performing a single-loop learning. In the second case of learning, the information generated is used to review the set of goals, norms and standards of the organization, creating alternatives to dominant knowledge structures. As shown in Figure 4, the building blocks that comprise the analytical model are illustrated by the organizational context focused in this paper.

- Dominant knowledge structures: they comprise Petrobras' standards, international standards, guidelines, basic design, technical regulations, relevant national legislation applied to LECPs in the oil and gas industry, as well as good engineering and project management practices;

- $\quad$ Action: refers to the development of FEED phase of the three marine terminals projects, as follows: (i) Pecém - Tecém (Ceará State); (ii) Barra do Riacho (Espírito Santo State); and (iii) Iltha Comprida (Rio de Janeiro State);

- $\quad$ Results: they correspond to the degree of compliance of respective contractors and subcontractors to technical and legal requirements applicable to FEED phase devel-

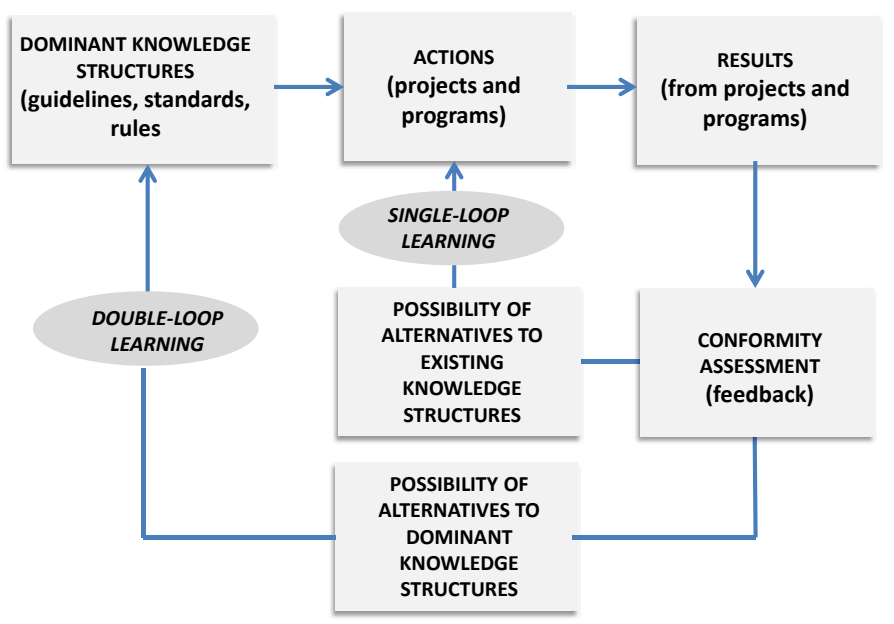

Figure 4.Analytical model of conformity assessment as a mechanism for organizational learning

ISSN: 07I 8-2724. (http://www.jotmi.org)

Journal of Technology Management \& Innovation (c) Universidad Alberto Hurtado, Facultad de Economía y Negocios. 
opment in the ambit of these projects. Include results of two types: (i) compliances and (ii) non-compliances;

- $\quad$ Conformity assessment (by third part): consists of the application of conformity assessment procedures by the certification body (Bureau Veritas Brazilian branch), for assessing compliance of results from the FEED phase of LECPs development. The results must be checked in relation to standards, basic design guidelines, best practices and contractual requirements between project owner (Petrobras) and engineering contractors;

- Critical analysis: aims to identify improvement actions applicable in cases of non-compliance of FEED phase identified during the conformity assessment by the third party. These improvement actions can be of three types: (i) corrective actions of current projects, (ii) proposals for revision of Petrobras standards, international standards, guidelines, basic designs, applicable technical regulations and relevant national legislation; and (iii) identification of good project management and engineering practices considered as innovative ones, that can contribute for generating and implementing new standards or revisions of regulatory documents;

- $\quad$ Changes in existing knowledge structures: the process of conformity assessment, particularly the analysis of the main errors detected in the FEED phase in relation to the technical and legal requirements, may enable changes in the existing knowledge structures within organizational environments of the actors involved in FFED phase (Petrobras project teams; engineering contractors and subcontractors, Bureau Veritas Brazilian branch and the client company of Petrobras, its subsidiary Transpetro);

- $\quad$ Single-loop learning: it arises when the results of conformity assessment by third party generate changes in FEED phase of the respective projects, based on the proposed corrective actions in the stage of critical analysis (after conformity assessment by Bureau Veritas);
- $\quad$ Changes in the dominant knowledge structures: the process of conformity assessment by the third party may generate proposals for revision of Petrobras standards, international standards, guidelines, basic designs, technical regulations etc. It can also help to create new performance standards based on good engineering and project management practices considered as innovative ones;

- Double-loop learning: it occurs when the projects' evaluation generates changes in the values of the organizations involved, as well as in their strategies and assumptions. In other words, double-loop learning is directly related to changes in dominant knowledge structures.

\section{Results}

Due to its simplicity and didactic format, the analytical model provided a practical framework for any doubts relating to a total of 7,650 project documents, as well as discussion of alternatives between the authors and respective project teams within the certification body (Bureau Veritas) and the project owner (Petrobras).

The main question of the case study here presented was to analyze to what extent the conformity assessment of LECPs, particularly the results from FEED phase, can be used as a tool for organizational learning and cooperation between typical stakeholders (project owners, engineering contractors, EPC contractors; subcontractors and certification bodies). Due to space limitation, we present in this paper only the results related to Terminal I project, based on the accurate analysis of 1,095 documents.

First, we highlight the critical documents from FEED phase of this project, i.e., those with a greater number of errors during its elaboration and for which revisions were indicated. Then, we map the major errors arising from the incom-

\begin{tabular}{|l|l|l|}
\hline Criticality & Description & Documents revisions \\
\hline High & $\begin{array}{l}\text { Document analyzed three or more } \\
\text { times by the certification organism } \\
\text { before meeting all comments in the } \\
\text { document under review. }\end{array}$ & C,D,E or more. \\
\hline Medium & $\begin{array}{l}\text { Document analyzed two times by the } \\
\text { certification organism before meeting } \\
\text { all comments in the document under } \\
\text { review. }\end{array}$ & B \\
\hline Low & $\begin{array}{l}\text { Document only once by the certifi- } \\
\text { cation organism before meeting all } \\
\text { comments in the document under } \\
\text { review. }\end{array}$ & A \\
\hline
\end{tabular}

Table 2. Criticality criteria used in conformity assessment of documents from FEED phase

ISSN: 07 I8-2724. (http://www.jotmi.org)

Journal of Technology Management \& Innovation (c) Universidad Alberto Hurtado, Facultad de Economía y Negocios. 
patibility between the disciplines involved (electrical, civil, instrumentation and automation, and process piping) or due to non-compliance with requirements defined by Petrobras or established in technical regulations and applicable legislation. The set of 1,095 documents from Terminal I Project was analyzed according to the criterion of criticality. The documents were classified as being of high, medium and low criticality, as described in Table 2.

\section{Critical documents}

The results of the criticality of the documents generated in the FEED phase of Terminal I project were first analyzed by discipline, and in a second level, by type of document in each discipline. By way of illustration, we present the results of the criticality analysis of documents related to the discipline "instrumentation" in two levels (Table 3 and Figure 5).

The set of documents relating to the discipline of instrumentation comprised 159 documents, and this discipline was responsible for $14.5 \%$ of all documents produced in FEED phase of the project. From this total, three documents were classified as being of low level of criticality; I4 as of medium criticality; and I42 documents were classified with high degree of criticality, i.e. almost $90 \%$ of the total.

According to the results showed in Figure 5, we can observe that three categories stand out as the ones that have more documents classified as highly critical concerning the discipline of instrumentation, namely: (i) materials requisition (RM) lead with $30 \%$, followed by data sheets (FD), with $27 \%$, and drawings (DE), with $26 \%$. It is worth noting that, according to the results from Table 3, from the total of 159 instrumentation documents, 142 refer to documents highly critical $(89 \%$ of the total documentation of instrumentation of FEED phase of Terminal I project).

Tables and graphs like the examples above were also generated for the other disciplines, namely: electrical, civil, process, and piping. With these results, it was possible to map the major errors arising from the incompatibility between the disciplines, highlighting the documents of medium and high criticality or derived from non-compliance with the legal requirements or technical requirements defined in Petrobras or international standards, when applicable. The focus of critical analysis was on documents relating to those dis-

\begin{tabular}{|l|l|l|l|l|l|}
\hline Discipline & Document category & Range of criticality & Total & & \\
\hline Instrumentation & Drawing & 0 & 0 & 37 & 37 \\
\hline & Technical specification & 0 & 0 & $\mathrm{I}$ & $\mathrm{I}$ \\
\hline & Data sheet & $\mathrm{I}$ & 3 & 39 & 43 \\
\hline & List & $\mathrm{I}$ & $\mathrm{II}$ & 19 & $3 \mathrm{I}$ \\
\hline & Material requisition & $\mathrm{I}$ & 0 & 43 & 44 \\
\hline & Project description & 0 & 0 & 3 & 3 \\
\hline Total & 6 & 3 & $\mathrm{I}$ & $\mathrm{I} 42$ & 159 \\
\hline
\end{tabular}

Table 3. Terminal I project: critical documents concerning intrumentation discipline

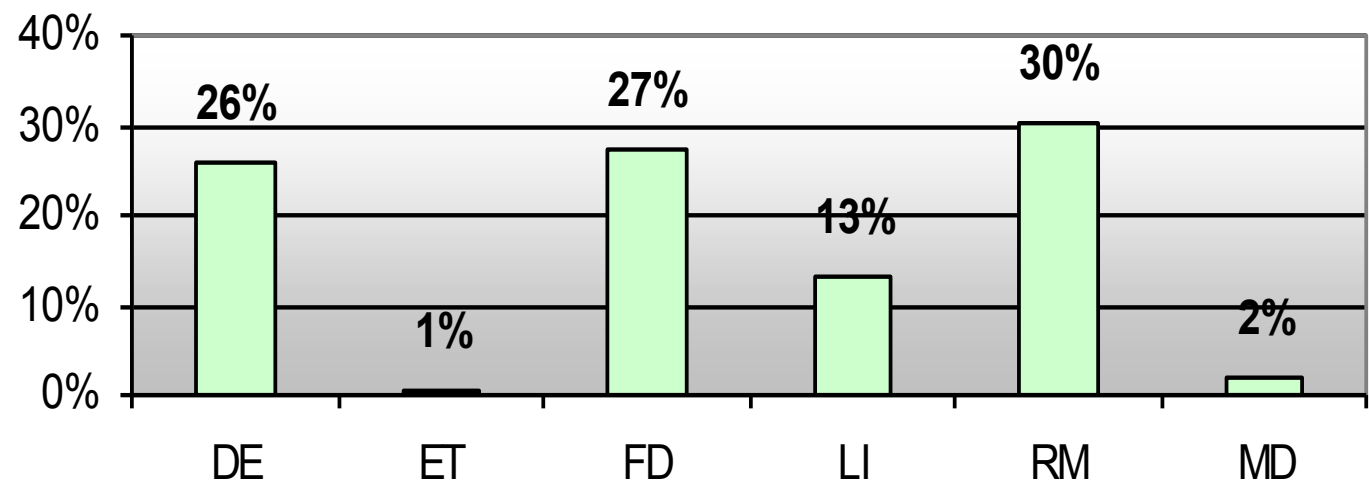

Legend: DE - Drawings, ET -Technical specifications; FD - Data sheets, LI - Lists, RM - Materials requisitions, MD - Project descriptions. Figure 5. Terminal I project: analysis by category of documents concerning discipline of instrumentation

ISSN: 07 I8-2724. (http://www.jotmi.org)

Journal of Technology Management \& Innovation (c) Universidad Alberto Hurtado, Facultad de Economía y Negocios. 
ciplines identified as the most critical in terms of number of errors and revisions in their documents. Following, we show the results from the third step.

\section{Mapping of the major errors during the FEED phase}

According to the classification of documents in terms of their criticality in FEED phase of Terminal I Project, Table 2 presents a summary of the major errors found in the documents of instrumentation considered as of high criticality. They are data sheets, material requisitions, and drawings.

As can be observed, the major errors were originated from the incompatibility between disciplines or due to non-compliance with requirements defined in Petrobras' standards.

From the empirical evidence obtained from conformity assessment of the three Petrobras' LECPs (FEED phase), it was possible to establish connections between the conformity assessment rationale and the organizational learning approach, as schematically showed in Figure 4. During the case study development, it was perceived that several actors involved in the learning process supported by conformity assessment mechanism could receive constructive feedback from relevant information associated to critical engineering documents and systematic errors in the FEED phase.

Within the systemic organizational learning framework, as here proposed, this kind of information can be clearly perceived, easily monitored, and errors can be systematically avoided with corrective and preventive actions. In consequence, this feedback process can generate significant economic impacts in the subsequent phases of LECPs, by singleloop learning cycles or even double-loop learning cycles, as conceived by Argyris and Schön (1996) and discussed in previous sections.

The evidences from the three projects also showed the possibility of co-occurrence of single-loop and double-loop learning cycles. Through the process of conformity assessment one can also identify the need for reviewing project specifications or creating new parameters and requirements during the definition phase. In another words, normative documents can be reviewed in function of errors detected and improper engineering practices. Such double-loop learning cycles, in turn, will require new knowledge from those stakeholders involved (project owner, engineering contractors, subcontractors and certification body).

\begin{tabular}{|l|l|}
\hline Category & Type of error \\
\hline Data sheets (FD) & Non-compliance with requirements defined in Petrobras N-I882 standard. \\
\hline & $\begin{array}{l}\text { Several important parameters for the correct specification of the instru- } \\
\text { ments are not informed. }\end{array}$ \\
\hline & Incompatibility of operating conditions with process documentation. \\
\hline Material requisitions (RM) & $\begin{array}{l}\text { The instruments are not located as indicated in the floor plan, flowchart and/ } \\
\text { or isometrics. }\end{array}$ \\
\hline & $\begin{array}{l}\text { The quantitative of material requisition and descriptions of the materials are } \\
\text { not in compliance with reference documents. }\end{array}$ \\
\hline Drawings (DE) & $\begin{array}{l}\text { Some materials and accessories listed in the reference documents are not } \\
\text { informed in material requisitions. }\end{array}$ \\
\hline & $\begin{array}{l}\text { Non-compliance with requirements defined in Petrobras N-I93I and N-76 } \\
\text { standards. }\end{array}$ \\
\hline & $\begin{array}{l}\text { In the drawings of routing cables are not indicated the dimensions of ducts } \\
\text { and conduits, materials which are employed, instrumentation wiring, layout of } \\
\text { instruments. }\end{array}$ \\
\hline & $\begin{array}{l}\text { Lack of details and information on the drawings concerning the electrical } \\
\text { installation, pneumatic and the process. }\end{array}$ \\
\hline $\begin{array}{l}\text { Incompatibility of the drawings of instruments layout and the cable routing } \\
\text { with the reference documents, especially with lists of cables, flowcharts, floor } \\
\text { plants and architecture project. }\end{array}$ \\
\hline Lack of information as cuts, views and details. \\
\hline Incompatibility with requirements defined in Petrobras N-I883. \\
\hline
\end{tabular}

Table 2. Major errors identified in FEED phase of Terminal I project: discipline of instrumentation

ISSN: 07 I8-2724. (http://www.jotmi.org)

Journal of Technology Management \& Innovation (c) Universidad Alberto Hurtado, Facultad de Economía y Negocios. 


\section{Conclusions}

This research contributed to empirical knowledge basis concerning the importance of conformity assessment as an effective mechanism for organizational learning during the development of large engineering and construction projects (LECPs). Accordingly, a case study was carried out focusing on three LECPs conducted in the oil and gas industry, particularly by Petrobras Engineering Services in Brazil. The FEED phase of each project was audited by the Brazilian branch of Bureau Veritas and conformity assessment results indicated a real opportunity to the respective stakeholders' project teams to learn from major errors in FEED phase and adopt a preventive posture for next steps.

Among the 7,650 engineering documents analyzed in this research, 2, 169 were considered highly critical (28\%); 2,904 documents being of medium criticality (27\%), and 3,387 of low criticality. The documents that have suffered more than one review (medium and high criticality) represent $56 \%$ of the total of analyzed documents. In general, the disciplines with the largest number of documents of high and medium criticality are civil engineering, piping, electrical and instrumentation. It was also possible to identify the major errors arising from the incompatibility between the disciplines involved or due to non-compliance with requirements defined in Petrobras internal standards or applicable legal requirements (technical regulations and legislation).

Regarding the three engineering projects, there was plenty of evidence of single-loop learning, mainly related to errors in critical documents, such as incompatibility between documents from different disciplines, non-compliance with Petrobras' standards requirements, lack of data and information on floor plan drawings, data sheets, isometrics, as well as and limitation or imprecision of some critical information. Double-loop learning has been also observed in the case study. By way of illustration, reviews of descriptive text and drawings related to the overall architecture of the project for Marine Terminal of Barra do Riacho, situated in Espírito Santo State. Another example of double-loop learning refers to the need for creating new business standards, especially those related to the discipline of instrumentation, in general, and to requirements of instrumentation data sheets, in particular.

Based on the research results, we can conclude that the proposed organizational learning framework, supported by the conformity assessment rationale, constitutes an important management tool that can be disseminated in other organizational contexts where conformity assessments of LECPs take place. Finally, for the purpose of future adoption of the model in other Petrobras' LECPs, we suggest that research propositions and recommendations are addressed to LECPs' managers involved, as well as to certification body responsible for the contract of conformity assessment object of this research.

\section{References}

ARGYRIS, C., Schön, D. A. (1996). Organizational learning II: theory, method and practice. Reading. Mass: Aisson Wesley, $305 \mathrm{p}$.

BERENDS, K. (2007). Engineering and construction projects for oil and gas processing facilities: contracting, uncertainty and the economics of information. Energy Policy, v.35, p. $4260-4270$.

BERENDS,T. C. (2009). Contracting economics of large engineering and construction projects. Thesis (PhD). University of Delft. Netherlands.

BRITISH PETROLEUM (20I2). Energy Outlook 2030. Statistical Review 2012. London: British Petroleum.

FIOL, C. M.; Lyles, M.A. (1985). Organizational learning.Academy of Management Review, v. 10, p. 803-813.

FORSS, K., Cracknell, B., Samset, K. (1994). Can evaluation help an organization to learn? Evaluation Review, v. I8, n. 5, p. 574-59l.

ISO. IEC (2005). ISO/IEC I7000:2005 - Conformity assessment - Vocabulary and general principles. ISO/IEC.

KERKHOF, M.; Wieczoreck, A. (2005). Learning and Stakeholder Participation in Transition Processes Towards Sustainability: Methodological Considerations. Technological Forecasting \& Social Change, v.72, p.733-747.

LOWES, N., Van Driel, J. P. (2004). Too much of a good thing? Petroleum Review, Energy Institute, London.

MERROW, E.W. (20I I). Industrial megaprojects: concepts, strategies, and practices for success. New Jersey: John Wiley \& Sons.

ROOIJVAN, A., Homburg, E. (2002). Building the plant: a history of engineering contracting in the Netherlands. Walburg Pers, Zutphen, The Netherlands.

RUFINO, S. (20I I). Importância do projeto no empreendimento. http://bt.fatecsp.br/system/articles/I I7/original/trabalho7.pdf. [Accessed in April 20 I3]. 
RUSS-EFT, D., Preskill, H. (200I). Evaluation in organizations: a systematic approach to enhancing learning, performance, and change. Boston, MA: Perseus Books.

SENGER, E.C. (20I2). Petroleum projects: towards a relationship of level of definition and contracting strategies.Australia, 20I2. I26 p. (MSc. in Energy and Resources) - UCL School of Energy and Resources. Australia.

TORRES, R.T., Preskill, H. (200I). Evaluation and organizational learning: past, present, and future. American Journal of Evaluation, v.22, n.3, p. 387-395.

YIN, R.K. (2005). Case study research: design and methods. 3rd. ed.Thousand Oaks: Sage Publications. 